\title{
Selective HIF-1 Regulation under Nonhypoxic Conditions by the p42/p44 MAP Kinase Inhibitor PD184161ฐ
}

\author{
Maroua Jalouli, Sophie Mokas, Catherine A. Turgeon, Laurent Lamalice, \\ and Darren E. Richard \\ Centre de recherche du CHU de Québec, Department of Molecular Biology, Medical Biochemistry and Pathology, Université \\ Laval, Québec City, Québec, Canada
}

Received March 3, 2017; accepted August 2, 2017

\begin{abstract}
Hypoxia-inducible factor-1 (HIF-1) is a key gene regulator for cellular adaptation to low oxygen. In addition to hypoxia, several nonhypoxic stimuli, including hormones and growth factors, are essential for cell-specific HIF-1 regulation. Our studies have highlighted angiotensin II (Angll), a vasoactive hormone, as a potent HIF-1 activator in vascular smooth muscle cells (VSMC). Angll increases HIF-1 transcriptional activity by modulating specific signaling pathways. In VSMC, p42/p44 mitogen-activated protein kinase (MAPK) pathway activation is essential for HIF-1-mediated transcription during Angll treatment. The present study shows that PD184161, a potent MEK1/2 inhibitor, is an HIF-1 blocker in Ang II-treated VSMC. Unlike PD98059, a widely-used MEK1/2 inhibitor, we found that PD184161 blocked Angll-driven HIF-1 $\alpha$ protein induction in a dose-dependent manner. Interestingly, the effect of PD184161 was specific to nonhypoxic activators, since HIF-1 $\alpha$
\end{abstract}

induction by hypoxia $\left(1 \% \mathrm{O}_{2}\right)$ was unaffected under similar conditions. VSMC treatment with MG132, a proteasome inhibitor, indicated that PD184161 influenced HIF-1 $\alpha$ protein stability. PD184161 also increased HIF-1 $\alpha$ binding to von Hippel-Lindau tumor suppressor protein, an E3 ligase component and an indication of HIF- $1 \alpha$ hydroxylation. Finally, we show that PD184161 blocked mitochondrial ROS (mtROS) production and cellular ATP levels, at the same time enhancing ascorbate availability in Angll-treated VSMC. Taken together, our study indicates that, independently of p42/p44 MAPK activation, PD184161 blocks mtROS generation by Angll, leading to re-establishment of cellular ascorbate levels, increased VHL binding, and decreased HIF-1 $\alpha$ stability. Therefore, this study reveals a previously unsuspected role for PD184161 as an HIF-1 inhibitor in VSMC under nonhypoxic conditions.

\section{Introduction}

Hypoxia-inducible factor-1 (HIF-1) is an essential transcription factor for all cells that regulate cellular adaptation responses to low oxygen $\left(\mathrm{O}_{2}\right)$ availability (Semenza, 2003). Transcriptionally active HIF-1 is a heterodimeric complex composed of a stable HIF- $1 \beta$ subunit and an oxygen-sensitive HIF- $1 \alpha$ subunit. HIF-1 is mainly regulated by proteasomal degradation, a mechanism under the control of oxygensensitive HIF prolyl hydroxylase domain-containing enzymes

This work was supported by research grants to D.E.R. from the Canadian Institutes of Health Research (CIHR; MOP-102760) and the Heart and Stroke Foundation of Québec. S.M. and C.A.T. received graduate scholarships from the Fonds de recherche du Québec-Santé (FRQS). All authors declare no competing interests.

https://doi.org/10.1124/mol.117.108654.

S This article has supplemental material available at molpharm.aspetjournals.

ABBREVIATIONS: Angll, angiotensin II; $\mathrm{CoCl}_{2}$, cobalt chloride; DMEM, Dulbecco's modified Eagle's medium; EGFR, epidermal growth factor receptor; GST, glutathione S-transferase; HA, hemagglutinin; HIF-1, hypoxia-inducible factor-1; MAPK, mitogen-activated protein kinase; MG132, benzyl $N$-[(2S)-4-methyl-1-[[(2S)-4-methyl-1-[[(2S)-4-methyl-1-oxopentan-2-yl]amino]-1-oxopentan-2-yl]amino]-1-oxopentan-2-yl]carbamate; mito$\mathrm{K}_{\mathrm{ATP}}$, mitochondrial ATP-sensitive potassium channel; mtROS, mitochondria-derived reactive oxygen species; ODDD, oxygen-dependent degradation domain; PD184161, 5-bromo-2-[2-chloro-4-iodo-phenylamino]-N-cyclopropylmethoxy-3,4-difluoro-benzamide; PD98059, 2-(2amino-3-methoxyphenyl)-4H-chromen-4-one; PDGF, platelet-derived growth factor; PHD, HIF prolyl hydroxylase domain-containing enzymes; qRT-PCR, real-time quantitative reverse transcription-polymerase chain reaction; S1P, sphingosine-1-phosphate; SkQ1, 10-(6'-plastoquinonyl) decyltriphenylphosphonium; Thr, thrombin; TMRM, tetramethylrhodamine methyl ester; U0126, 1,4-diamino-2,3-dicyano-1,4-bis(2aminophenylthio)butadiene; VHL, von Hippel-Lindau tumor suppressor protein; VSMC, vascular smooth muscle cells. 
HIF-1 transcription complex. HIF-1 binds to specific hypoxia response elements (HRE) found within target genes promoters, resulting in adaptive gene activation. HIF-1 activation is also dependent on HIF-1 $\alpha$ phosphorylation by $\mathrm{p} 42 / \mathrm{p} 44$ mitogenactivated protein kinases (MAPK) (Richard et al., 1999; Minet et al., 2000; Hur et al., 2001; Sodhi et al., 2001; Fukuda et al., 2002; Lee et al., 2002; Sutton et al., 2007). HIF-1 $\alpha$ phosphorylation permits binding by a proline isomerase, Pin1, which is indispensable for full HIF-1 transcriptional activity. (Jalouli et al., 2014; Han et al., 2016).

Under normal $\mathrm{O}_{2}$, HIF-1 is also activated by different cellular stimuli, a condition we described as nonhypoxic HIF-1 activation. Vascular smooth muscle cells (VSMC) show nonhypoxic HIF-1 activation following cell treatment with different receptor agonists, including angiotensin II (AngII), platelet-derived growth factor (PDGF), sphingosine-1-phosphate (S1P), and thrombin (Thr) (Richard et al., 2000; Michaud et al., 2009). Distinct mechanisms come together for nonhypoxic HIF-1 activation in VSMC, including transcriptional and translational upregulation (Richard et al., 2000; Pagé et al., 2002, 2008; Lauzier et al., 2007; Patten et al., 2010). HIF-1 $\alpha$ protein stabilization is arguably the main mechanism for HIF-1 activation under these conditions. By stimulating mitochondria-derived reactive oxygen species (mtROS) generation, AngII treatment causes a pro-oxidative intracellular microenvironment, which leads to ascorbate depletion, PHD inhibition, and finally HIF-1 $\alpha$ stabilization (Pagé et al., 2008; Patten et al., 2010).

In this study, we show that PD184161 (5-bromo-2-[2-chloro4-iodo-phenylamino]- $N$-cyclopropylmethoxy-3,4-difluorobenzamide) abolishes AngII-induced HIF-1 activation in VSMC independently of p42/p44 MAPK activity. PD184161 is a potent and selective inhibitor of MEK1/2 ( $\left.\mathrm{IC}_{50}=10-100 \mathrm{nM}\right)$. Biologically active in plasma and more effective at inhibiting p42/p44 MAPK activation than other MEK1/2 inhibitors (PD98059, U0126), PD184161 has been useful for studying both the in vitro and in vivo roles of the Raf/MEK/MAPK pathway (Marshall et al., 2004; Thottassery et al., 2004; Klein et al., 2006). We demonstrate that PD184161 restores VHLHIF-1 $\alpha$ binding and HIF-1 $\alpha$ degradation that was lost during AngII treatment. Finally, we show that PD184161 decreases AngII-induced mtROS generation and re-establishes cellular ascorbate levels, which is essential for HIF- $1 \alpha$ hydroxylation and destabilization. Taken together, our work identifies PD184161 as a potent inhibitor of nonhypoxic HIF-1 induction in VSMC.

\section{Materials and Methods}

Materials. AngII, cobalt chloride $\left(\mathrm{CoCl}_{2}\right)$, PD98059, PD184161, PDGF, and thrombin were from Sigma-Aldrich (St. Louis, MO). S1P and MG132 were from EMD Millipore (Billerica, MA). MitoSOX and tetramethyl rhodamine methyl ester (TMRM) were from Thermo Fisher Scientific (Waltham, MA). SkQ1 was from Dr. Vladimir Skulachev at Moscow State University (Skulachev et al., 2009). Polyclonal anti-HIF-1 $\alpha$ antibody was raised in our laboratory using rabbits immunized against the last 20 amino acids of the C-termini of the human protein (Richard et al., 1999). The monoclonal antiphospho-p42/p44 MAPK antibody was from Sigma-Aldrich, whereas the polyclonal anti-p42/p44 MAPK was from EMD Millipore. Antiglutathione $S$-transferase (GST) antibody was from Novus Biologicals (Littleton, CO). Monoclonal HA.11 antibody was from Covance (Emeryville, CA). Horseradish peroxidase-coupled anti-mouse and antirabbit antibodies were from Promega (Madison, WI). GST-HIF- $1 \alpha$ fusion protein, VHL-hemagglutinin (HA), luc-HIF-1 $\alpha$-ODDD constructs, and pHIF-1A-572/+32Luc reporter vector were kind gifts from Dr. Jacques Pouysségur (University of Nice-Sophia Antipolis), Dr. Peter Ratcliffe (University of Oxford), Dr. Richard K. Bruick (University of Texas Southwestern), and Dr. Gregg Semenza (Johns Hopkins University), respectively.

Cell Culture. VSMC were isolated from thoracic aortas of 6-weekold male Wistar rats by enzymatic dissociation (Owens et al., 1986). Cells were grown in Dulbecco's modified Eagle's medium (DMEM) containing $12.5 \%$ fetal bovine serum and supplemented with antibiotics $(50 \mathrm{IU} / \mathrm{ml}$ penicillin and $50 \mu \mathrm{g} / \mathrm{ml}$ streptomycin) and $2 \mathrm{mM}$ glutamine (Thermo Fisher Scientific). In all experiments, cells were deprived of serum 16 hours prior to treatment. Hypoxic conditions were achieved by incubating cells in a sealed hypoxic workstation (Baker Ruskinn, Bridgend, UK). Oxygen levels in the workstation were maintained at $1 \%$ with a residual gas mixture containing $94 \%$ nitrogen and $5 \% \mathrm{CO}_{2}$.

Western Blot Analysis. VSMC were lysed in $2 \times$ Laemmli sample buffer. Lowry assay was used to determine protein concentration. Cell lysates were resolved on SDS-polyacrylamide gels and then electrophoretically transferred to polyvinylidene difluoride membranes (Immobilon-P; EMD Millipore). Proteins of interest were analyzed using the indicated antibodies and visualized with the Odyssey Infrared Imaging System (LI-COR, Lincoln, NE) or with enhanced chemiluminescence system (GE Healthcare Life Sciences, Piscataway, $\mathrm{NJ}$ ). Western blots were quantified using Odyssey Application software v.3.1 (LI-COR). Results are representative of at least three independent experiments.

Real-Time Quantitative Reverse Transcription-Polymerase Chain Reaction. RNA was isolated from VSMC using TRIzol per the manufacturer's protocol (Thermo Fisher Scientific). RNA purity was assessed by Nanodrop (Thermo Fisher Scientific). Reverse transcription was performed with qScript cDNA SuperMix (Quanta Biosciences, Gaithersburg, MD). Real-time quantitative reverse transcription-polymerase chain reaction (qRT-PCR) was performed on an MX3005P system (Agilent Technologies, Santa Clara, CA) using Perfecta SYBR Green SuperMix, Low ROX kit (Quanta Biosciences). The primer pair used for rat HIF-1 $\alpha$ (accession no. NM_024359) was fwd: 5' -CTTCTGATGGAAGCACTAGACAA-3', rev: 5' -TTCCAAGTCTAAATCAGTGTCCT-3' . Rat HPRT1 (accession no. NM_012583) was used as a reference gene (fwd: 5 '-CAGTCCCAGCGTCGTGATTAGT3', rev: 5'-ATCCAGCAGGTCAGCAAAGAAC-3'). The expression of each gene of interest relative to HPRT1, a reference gene, was calculated on the basis of the threshold cycle $(\mathrm{Ct})$ using the Pfaffl formula (Pfaffl, 2001). Results are presented as a percent change calculated by comparing the treated sample with its corresponding control condition as indicated.

Luciferase Assay. Cells were seeded in 12-well plates and transfected by SuperFect Transfection Reagent (Qiagen, Valencia, CA) at a 1: $3 \mathrm{DNA} /$ reagent ratio with $2 \mu \mathrm{g} /$ well of either luc-HIF-1 $\alpha$-ODDD or pHIF-1A-572/+32Luc luciferase reporter vectors. Renilla reniformis luciferase expression vector ( $25 \mathrm{ng} /$ well) was used to control transfection efficiency. Forty-eight hours post-transfection, cells were serumdeprived for 16 hours and treated as indicated. The Dual Luciferase Reporter Assay System (Promega) was used for luciferase assays. Measurements were performed on a Luminoskan Ascent microplate reader with integrated injectors (Thermo Fisher Scientific). Results are expressed as a ratio of firefly luciferase activity over Renilla reniformis luciferase activity. Experiments are an average \pm S.D. of triplicate data representative of three independent experiments.

VHL Capture Assay. VHL capture assay was performed as previously described (Pagé et al., 2008). Briefly, cells were grown to confluence, deprived of serum for 16 hours, treated as indicated, and then lysed. Cytoplasmic extracts $(250 \mu \mathrm{g})$ were incubated with Sepharosebound GST-HIF-1 $\alpha(50 \mu \mathrm{g})$ for 1 hour at room temperature and then washed with NETN buffer (150 mM NaCl, $0.5 \mathrm{mM}$ ethylenediamine tetraacetic acid, $20 \mathrm{mM}$ Tris $\mathrm{pH} 8.0,0.5 \%$ Igepal, and $100 \mu \mathrm{M}$ DFO) prior to incubation with in vitro-translated VHL-HA in NETN buffer overnight 
at $4^{\circ} \mathrm{C}$ with rotation. Sepharose-bound GST-HIF- $1 \alpha$ was then washed with NETN buffer and suspended in $2 \times$ Laemmli sample buffer. Samples were resolved in SDS-polyacrylamide gels, transferred to polyvinylidene difluoride, and revealed using Western blot analysis with specific antibodies as indicated.

mtROS Assay. Mitochondrial ROS production was determined using MitoSOX Red mitochondrial superoxide indicator (Thermo Fisher Scientific), which is selectively targeted to the mitochondria and is fluorescent upon ROS oxidation. MitoSOX was used per manufacturer's protocol. Briefly, cells seeded on glass-bottomed cell culture dishes were serum-deprived overnight in phenol red-free DMEM and then incubated with MitoSOX $(1 \mu \mathrm{M})$ for 1 hour before imaging. VSMC were treated with or without PD184161 for 20 minutes prior to incubation with AngII during the final 20 minutes. Cell imaging was performed with FV1000 confocal microscope equipped with a live cell apparatus ( $60 \times$ oil, $1.4 \mathrm{NA})$ driven by FluoView software (Olympus, Tokyo, Japan). Fluorescence quantification was performed using the Measure Integrated Density function of ImageJ (imagej.nih.gov).

Intracellular Ascorbate Assay. Ascorbate levels were analyzed by spectrophotometry using a modified protocol (Queval and Noctor, 2007). Briefly, VSMC were cultured in DMEM supplemented with $250 \mu \mathrm{M}$ ascorbate. Upon reaching confluence, cells were serum-deprived for 16 hours in ascorbate-supplemented DMEM. Fresh DMEM without ascorbate was added 1 hour prior to treatment. Cells were washed twice with phosphate-buffered saline, lysed in methanol, briefly sonicated, and centrifuged at 20,000g. Samples were diluted in $0.2 \mathrm{mM} \mathrm{NaH} \mathrm{PO}_{4}, \mathrm{pH}$ 5.6 , and absorbance was measured at $265 \mathrm{~nm}$. Ascorbate peroxidase $(0.4$ IU) was then added to samples for 15 minutes, and the absorbance was again measured at $265 \mathrm{~nm}$. Ascorbate concentrations were determined as the difference in absorbance before and after addition of ascorbate peroxidase. A Lowry protein assay was used for sample normalization.

ATP Assay. VSMC were serum-deprived overnight in low-glucose DMEM. Cells were treated as indicated, and intracellular ATP levels were measured with a luminescent ATP detection kit (Abcam, Cambridge, UK) according to the manufacturer's protocol using a Luminoskan Ascent microplate reader. A Lowry protein assay was used for sample normalization.

Mitochondrial Membrane Potential Measurements. Mitochondrial membrane potential $\left(\Delta \Psi_{\mathrm{M}}\right)$ was determined using tetramethyl rhodamine methyl ester. VSMC were pretreated as indicated prior to incubation with TMRM ( $200 \mathrm{nM})$ for 20 minutes. Cells were then washed and placed in phenol red-free DMEM. Live cell imaging was performed with an AxioObserver Z1 system using a $40 \times$ objective and a AxioCam MRm camera controlled by Zen 2 software (Carl Zeiss Microscopy, Oberkochen, Germany). Fluorescence quantification was performed using the Measure Integrated Density function of ImageJ (imagej.nih.gov).

Statistical Analysis. GraphPad Prism 5 software was used for statistical analyses of experiments. Statistical analysis on Figs. 1C and $4 \mathrm{~A}$ were performed using a one-way repeated measures analysis of variance (ANOVA) with a Newman-Keuls post-hoc test. Statistical analysis on Figs. 1A, 2, B and D, 4B, 5B, 6 and 7, B and C were performed using a two-way repeated measures ANOVA with a Bonferroni correction. Statistical analysis on Fig. 3B was performed using a three-way ANOVA with the Benjamini-Hochberg procedure. Results were deemed significant if they attained a 95\% confidence level $(P<0.05)$ and all comparisons were performed with an experiment-wise error rate (EER) of 0.05 .

\section{Results}

PD184161 Inhibits HIF-1 $\alpha$ Protein Induction Induced by AngII in VSMC. p42/p44 MAPK activation is essential for HIF-1 function (Richard et al., 1999; Mylonis et al., 2006; Sutton et al., 2007). In VSMC, HIF-1 is strongly induced by AngII, independently of oxygen availability (Richard et al., 2000). Through epidermal growth factor receptor (EGFR) transactivation, Ang II is a potent activator of $\mathrm{p} 42 / \mathrm{p} 44$ MAPK in VSMC, and HIF-1 activity is strongly linked to p42/p44 MAPK activation (Lauzier et al., 2007). However, HIF-1 $\alpha$ protein induction is only modestly affected by p42/p44 MAPK pathway inhibitors, such as PD98059. To more clearly investigate the role of p42/p44 MAPK in AngIIinduced HIF-1 activation in VMSC, we assayed a potent inhibitor of the p42/p44 MAPK pathway, PD184161. This MEK1/2 inhibitor was shown to strongly inhibit p42/p44 MAPK signaling at concentrations lower than $1 \mu \mathrm{M}$ (Klein et al., 2006). Theoretically, PD184161 should have fewer off-target effects. However, we were surprised to discover that VSMC pretreatment with low concentrations of PD184161 blocked HIF-1 $\alpha$ accumulation by AngII in a dose-dependent manner (Fig. 1A). As expected, VSMC pretreatment with PD98059 had only minor inhibitory effects on HIF-1 $\alpha$ induction by AngII (Fig. 1, B and C). It is important to note that the concentrations used for both inhibitors demonstrate similar effects on p42/p44 MAPK phosphorylation levels (Fig. 1B). These results indicate that PD184161 possesses a potent inhibitory effect on HIF- $1 \alpha$ protein accumulation when VSMC are treated with AngII. The effect of PD184161 on HIF- $1 \alpha$ is independent of p42/p44 MAPK pathway activation.

PD184161 Blocks Nonhypoxic HIF-1 $\alpha$ Induction. Our previous studies have shown that in VSMC, AngII activates HIF-1 through mechanisms that differ from hypoxia $\left(1 \% \mathrm{O}_{2}\right)$ (Pagé et al., 2002, 2008; Lauzier et al., 2007; Patten et al., 2010). We wanted to determine whether the effect of PD184161 on HIF-1 $\alpha$ induction was specific to cells treated in nonhypoxic conditions. VSMC were pretreated with PD184161 and then incubated under hypoxic condition $\left(1 \% \mathrm{O}_{2}\right)$ or treated with $\mathrm{CoCl}_{2}$, a potent inhibitor of HIF-1 hydroxylation that mimics hypoxia. As seen in Fig. 2, A and B, whereas PD184161 pretreatment blocked HIF-1 $\alpha$ protein induction by AngII, it was ineffective in blocking HIF-1 $\alpha$ protein induction by $1 \% \mathrm{O}_{2}$ or $\mathrm{CoCl}_{2}$ treatment. Other nonhypoxic activators are also known to induce HIF-1 $\alpha$ in VSMC. To determine whether HIF- $1 \alpha$ induction by other nonhypoxic stimuli is also affected by PD184161, we treated cells with thrombin and sphingosine-1-phosphate. Thr and S1P both induce HIF- $1 \alpha$ protein levels through mechanisms similar to those observed with AngII (Richard et al., 2000; Michaud et al., 2009). As seen in Fig. 2, C and D, PD184161 also decreased HIF-1 $\alpha$ accumulation by both Thr and S1P treatment in a fashion similar to that observed with AngII-treated VSMC. Similar results were also observed when VSMC were treated with PDGF (Supplemental Fig. 1). Taken together, our results indicate the selective inhibition of nonhypoxic HIF- $1 \alpha$ protein induction by PD184161 in VSMC.

PD184161 Blocks AngII-Induced HIF-1 $\alpha$ Stabilization. Since AngII modulates HIF-1 activation through different mechanisms, we first wanted to determine whether PD184161 treatment alters HIF- $1 \alpha$ gene transcription. To undertake these experiments, we evaluated the effect of PD184161 on HIF- $1 \alpha$ mRNA expression by performing qRT-PCR experiments. As seen in Supplemental Fig. 2, our results show that PD184161 had no significant effect on HIF-1 $\alpha$ mRNA levels either in the presence or absence of AngII. Additionally, PD184161 did not significantly affect expression levels of a reporter driven by the minimal HIF- $1 \alpha$ gene promoter (pHIF-1A-572/+32Luc, results not shown) in the presence or absence of AngII. Taken together, these results indicate that PD184161 does not modify HIF-1 $\alpha$ levels by blocking HIF-1 $\alpha$ gene transcription.

As mentioned previously, regulating HIF- $1 \alpha$ stability is the main mechanism by which AngII activates HIF-1 in VSMC (Pagé et al., 2008; Patten et al., 2010). We therefore 


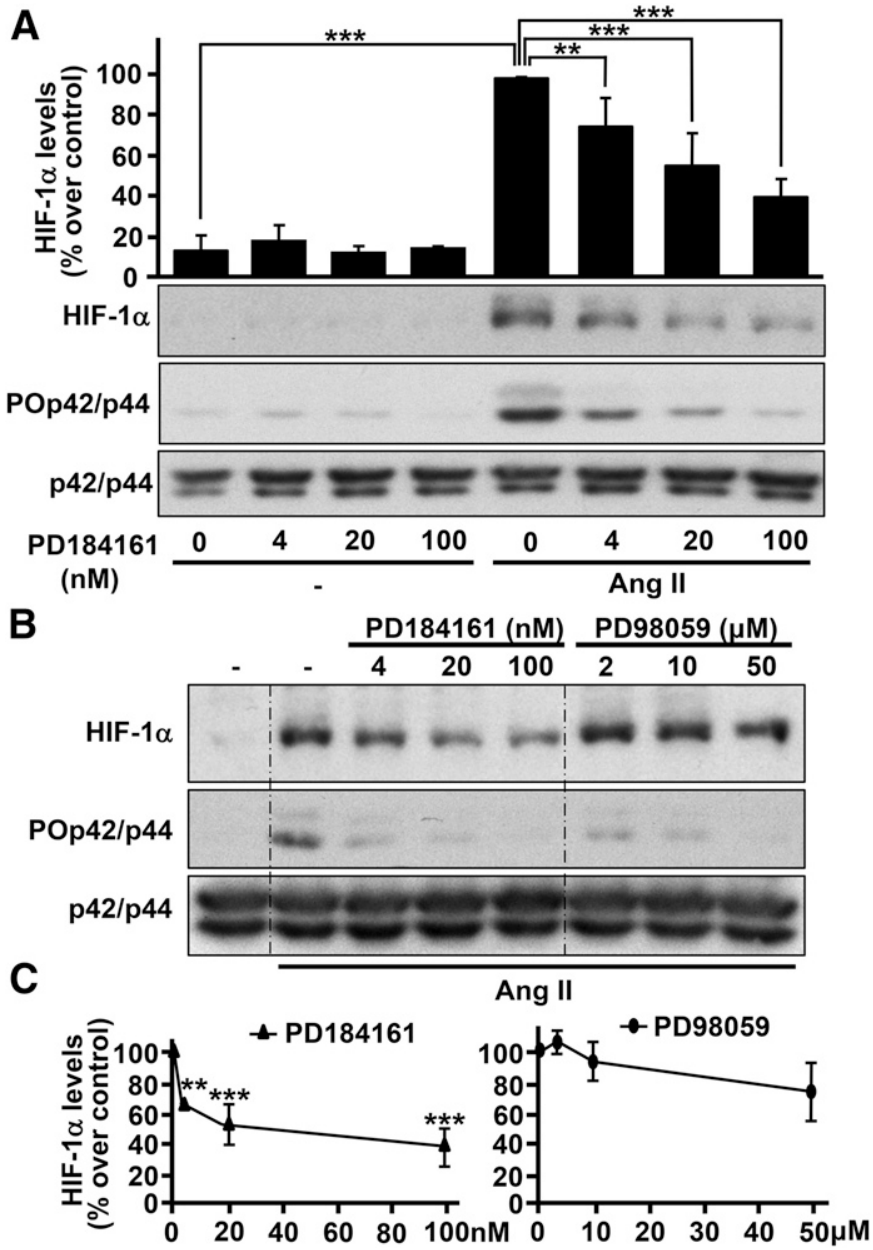

Fig. 1. AngII-induced HIF-1 $\alpha$ is inhibited by PD184161, an inhibitor of p42/p44 MAPK activation. (A) Quiescent VSMC were pretreated or not with PD184161 (at indicated concentrations) for 20 minutes and then treated with AngII $(100 \mathrm{nM})$ for 4 hours. Total extracts were resolved by SDS-PAGE and Western blotted with HIF-1 $\alpha$, phospho-p42/p44 (POp42/p44), and total$\mathrm{p} 42 / \mathrm{p} 44(\mathrm{p} 42 / \mathrm{p} 44)$ antibodies. Western blot experiments were quantified (upper panel) using the Odyssey Infrared Imaging System. Results are expressed as a ratio of the amount of HIF- $1 \alpha$ protein to the amount of total$\mathrm{p} 42 / \mathrm{p} 44$ protein and are an average with S.D. of three independent experiments. $* * P<0.01 ; * * * P<0.001$ compared with indicated conditions. (B) Quiescent VSMC were pretreated or not with PD184161/PD98059 (at indicated concentrations) for 20 minutes and then treated with AngII as previously described. (C) Western blot experiments were quantified using the Odyssey Infrared Imaging System. Results are expressed as a ratio of the amount of HIF- $1 \alpha$ protein to the amount of total-p42/p44 protein and are an average with S.D. of three independent experiments. $* * P<0.01$; *** $P<0.001$ compared with cells treated with AngII only.

investigated the impact of PD184161 on HIF-1 $\alpha$ protein stability by using MG132, a widely-used proteasome inhibitor. As expected, VSMC pretreatment with MG132 blocked HIF-1 $\alpha$ degradation and led to its accumulation in VSMC treated with or without AngII (Fig. 3, A and B). Interestingly, although HIF$1 \alpha$ protein levels were significantly reduced by PD184161 during AngII treatment, it was ineffective in the presence of MG132. This result indicated that in VSMC, PD184161 affected AngII-mediated changes in HIF-1 $\alpha$ protein stability prior to proteasomal degradation. VHL binding to hydroxylated HIF-1 $\alpha$ is a decisive step for HIF- $1 \alpha$ proteasomal degradation (Huang et al., 1998; Maxwell et al., 1999; Cockman et al., 2000; Ivan et al., 2001; Jaakkola et al., 2001). Since we have previously shown that in VSMC, AngII treatment increases HIF-1 $\alpha$

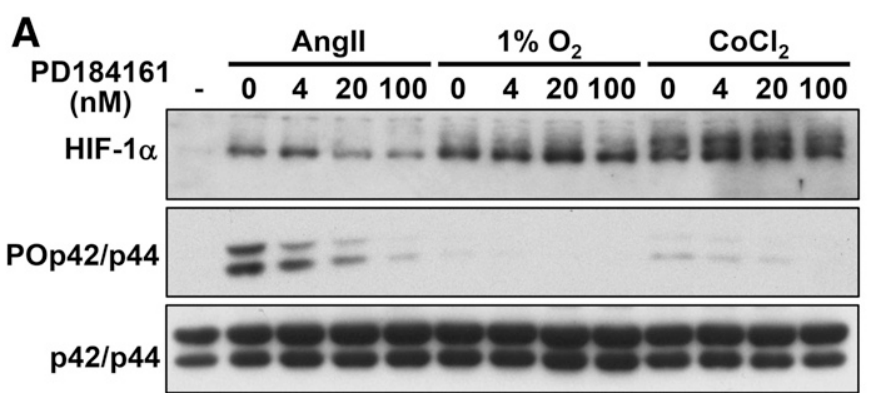

B
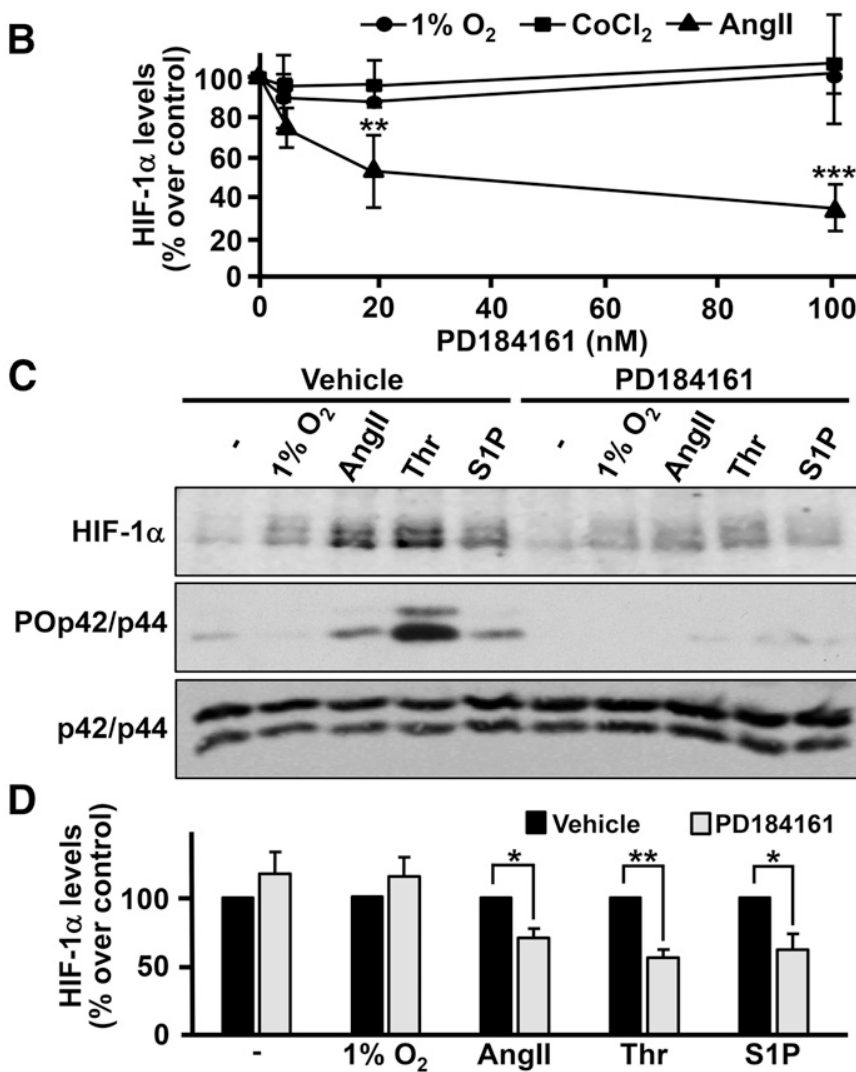

Fig. 2. HIF-1 $\alpha$ induction is selectively regulated by PD184161. (A) Quiescent VSMC were pretreated or not with PD184161 (at indicated concentrations) and then were treated with AngII $(100 \mathrm{nM}), 1 \% \mathrm{O}_{2}$ or cobalt $\left(\mathrm{CoCl}_{2}, 200 \mu \mathrm{M}\right)$ for $4 \mathrm{~h}$. Samples were resolved by SDS-PAGE and Western blotted with HIF$1 \alpha$, phospho-p42/p44 (POp42/p44) and total-p42/p44 (p42/p44) antibodies. (B) Western blot experiments were quantified using the Odyssey Infrared Imaging System. Results are expressed as a ratio of the amount of HIF-1 $\alpha$ protein to the amount of total-p42/p44 protein and are an average with SD of three independent experiments. $* * p<0.01$ and $* * * p<0.001$ as compared to treated cells without PD184161. (C) Quiescent VSMC were pretreated or not with PD184161 (50 nM) for 20 min and then treated with $1 \% \mathrm{O}_{2}$, AngII $(100 \mathrm{nM}), \mathrm{Thr}(5 \mathrm{U} / \mathrm{ml})$ and $\mathrm{S} 1 \mathrm{P}(2 \mu \mathrm{M})$ for $4 \mathrm{~h}$. Western blot was then used to analyze HIF-1 $\alpha$, POp42/p44 and p42/p44 levels. D) Western blot experiments were quantified using the Odyssey Infrared Imaging System. Results are expressed as a ratio of the amount of HIF-1 $\alpha$ protein to the amount of total-p42/p44 protein and are an average with SD of three independent experiments. ${ }^{*} p<0.05$ and ${ }^{* *} p<0.01$ as compared to indicated conditions.

stability by blocking PHD activity and subsequent VHL binding, we decided to investigate the effect of PD184161 on VHL-dependent HIF-1 $\alpha$ degradation (Pagé et al., 2008). First, we performed a VHL capture assay to determine HIF-1 $\alpha$ hydroxylation levels. A GST-HIF-1 $\alpha$ fusion protein, comprising amino acids 344-582 from human HIF-1 $\alpha$, was incubated with extracts of cells treated with AngII in the presence or absence of PD184161. These extracts were then incubated with HA-tagged 


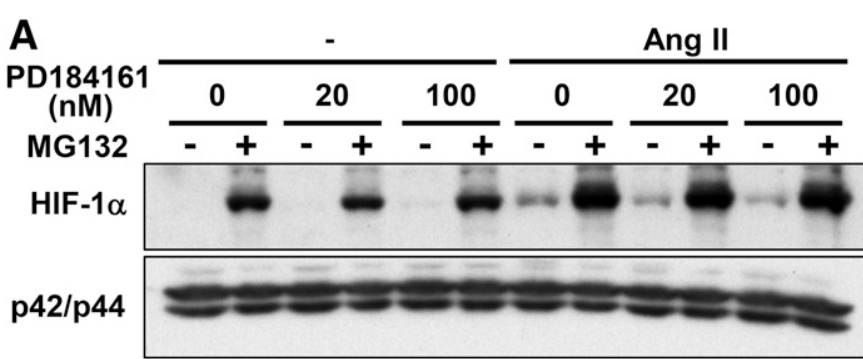

B $\square$ Vehicle $\square 20 \mathrm{nM}$ PD184161 $\square 100 \mathrm{nM}$ PD184161

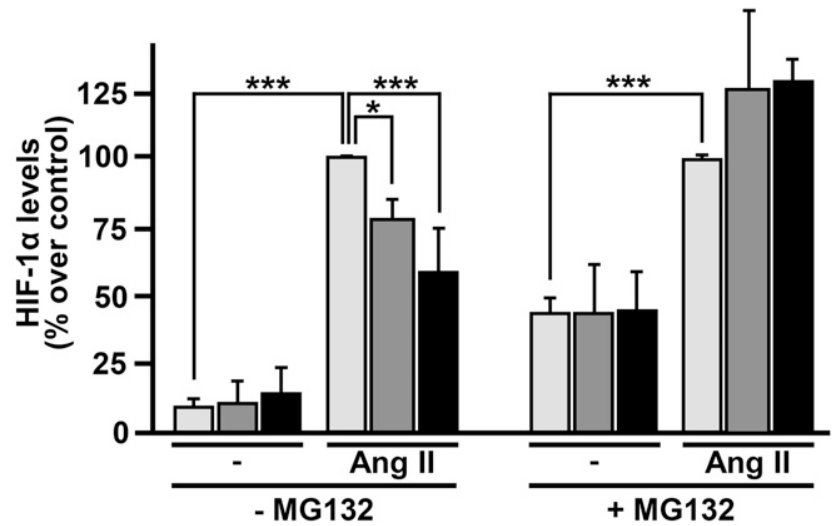

Fig. 3. Effect of PD184161 on HIF-1 $\alpha$ proteasomal degradation. (A) Quiescent VSMC were pretreated or not with MG132 $(10 \mu \mathrm{M})$ for 20 minutes prior to the addition or not of PD184161 (at indicated concentrations) for 20 minutes. VSMC were then treated with AngII (100 nM) for 4 hours. Samples were resolved by SDS-PAGE and Western blotted with antibodies against HIF-1 $\alpha$ and total-p42/p44 (p42/p44). (B) Western blot experiments were quantified with the Odyssey Infrared Imaging System using total-p42/p44 as a loading control. Results are expressed as the percentage of HIF- $1 \alpha$ levels compared with either vehicle + AngII- or to MG132 + AngII-treated cells and are an average with S.D. of three independent experiments. ${ }^{*} P<0.05$; *** $P<0.001$ compared with indicated conditions.

VHL translated in vitro. As seen in Fig. 4, A and B, VHL binding to HIF- $1 \alpha$ was significantly reduced in AngII-treated VSMC compared with untreated cells. As expected, the potent hydroxylase inhibitor $\mathrm{CoCl}_{2}$ completely blocked VHL binding to hydroxylated HIF-1 $\alpha$. More interestingly, decreased VHL binding to HIF- $1 \alpha$ observed under AngII treatment was reversed in cells pretreated with increasing concentrations of PD184161. Second, we used the luc-HIF-1 $\alpha$ ODDD construct in a luciferase assay to further determine how PD184161 regulates HIF-1 $\alpha$ stability. Luc-HIF-1 $\alpha$ ODDD encodes a fusion protein between firefly luciferase and HIF-1 $\alpha$ 's oxygen-dependent degradation domain. This construct contains two proline residues targeted for oxygen-dependent hydroxylation and, consequently, VHL binding (Salnikow et al., 2004). VSMC were transfected with luc-HIF$1 \alpha$ ODDD pretreated with PD184161 and then treated with AngII. As expected, AngII significantly increased luciferase activity in VSMC compared with untreated cells (Fig. 4C). More importantly, PD184161 pretreatment significantly blocked AngII-dependent luciferase activity in a dose-dependent manner. Of note, PD184161 had no effect on $\mathrm{CoCl}_{2}$-dependent luciferase activity using this same construct (results not shown). Taken together, these results indicate that PD184161 inhibits HIF-1 $\alpha$ stabilization during Ang II treatment by re-establishing HIF-1 $\alpha$ hydroxylation and VHL binding to the ODDD.

PD184161 Inhibits AngII-Induced Mitochondrial ROS Generation and Ascorbate Levels in VMSC. Our previous studies showed that increased mtROS production is

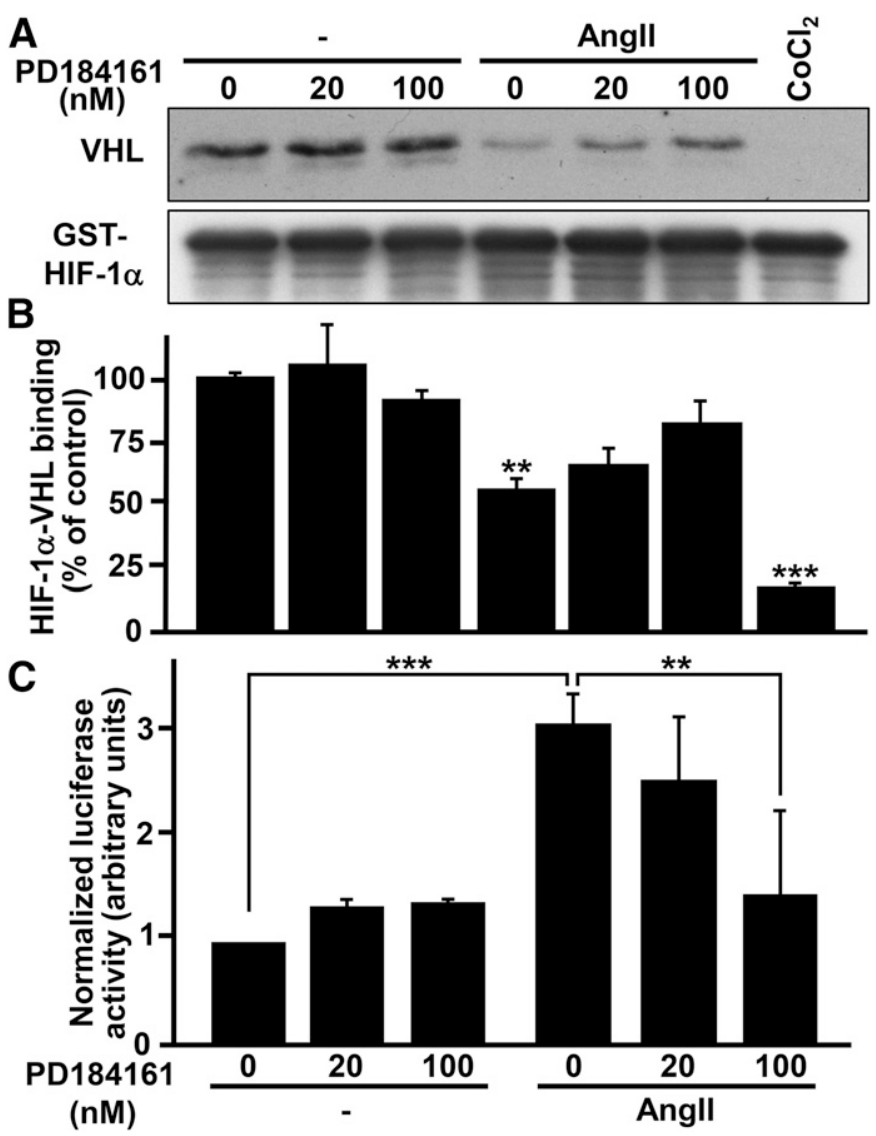

Fig. 4. PD184161 enhances HIF-1 $\alpha$ hydroxylation and VHL binding. (A) Quiescent VSMC were pretreated or not with PD184161 (at indicated concentrations) for 20 minutes. VSMC were then treated with AngII $(100 \mathrm{nM})$ or $\mathrm{CoCl}_{2}(200 \mu \mathrm{M})$ for 4 hours. GST-HIF- $1 \alpha$ coupled to Sepharose beads were incubated with cytoplasmic extracts for 1 hour followed by in vitro-translated VHL for 16 hours. Precipitates were resolved by SDSPAGE and Western blotted with HA (VHL) and GST antibodies. Western blot experiments were quantified (B) with the Odyssey Infrared Imaging System software using GST-HIF- $1 \alpha$ as a loading control. Results are expressed as the percentage of ratio of VHL levels compared with GSTHIF- $1 \alpha$ levels and are an average with S.D. of three independent experiments. ${ }^{* *} P<0.01 ; * * * P<0.001$ compared with untreated cells (vehicle only). (C) VSMC were transfected with $2 \mu \mathrm{g}$ of CMV-luc-HIF- $1 \alpha$ ODDD and $25 \mathrm{ng}$ of Renilla reniformis luciferase expression vectors. Fortyeight hours post-transfection, quiescent VSMC were pretreated or not with PD184161 (at indicated concentrations) for 20 minutes and treated with AngII (100 nM) for 4 hours. Cells were then lysed and luciferase activity was measured. Results are expressed as a ratio of firefly luciferase activity to $R$. reniformis luciferase activity and are an average with S.D. of three independent experiments performed in triplicate. $* * P<0.01$; $* * * P<0.001$ compared with indicated conditions.

responsible for decreasing cellular ascorbate levels and inhibiting PHD activity during AngII treatment (Pagé et al., 2008; Patten et al., 2010). Therefore, we wanted to determine whether PD184161 could also block AngII-induced mtROS production. Using MitoSOX, a mitochondria-targeted probe for detecting ROS, VSMC treated with AngII showed increased mtROS levels compared with untreated cells (Fig. 5, A and B). More importantly, VMSC pretreated with PD184161 showed a striking inhibition of mtROS levels. This result suggests that PD184161 decreases AngII-induced HIF-1 $\alpha$ stabilization by reducing mtROS generation in VSMC. Our previous work showed that cellular ascorbate levels are modified and closely linked to mtROS generation and HIF-1 activation in VSMC (Pagé et al., 2008; Patten et al., 2010). We 
therefore wanted to determine whether PD184161 could block decreased cellular ascorbate levels observed during AngII treatment. Using a protocol with differential spectrometric measurements as a basis, AngII treatment significantly decreased cellular ascorbate levels in VSMC (Fig. 6). When VSMC were treated with SkQ1, a mitochondria-targeted antioxidant, decreased intracellular ascorbate levels observed during AngII treatment were re-established. More importantly, pretreatment of VSMC with increasing concentrations of PD184161 restored intracellular ascorbate levels under AngII treatment. Taken together, our results indicate that PD184161 abrogates mtROS production by AngII treatment in VSMC and re-establishes intracellular ascorbate levels and HIF- $1 \alpha$ destabilization under nonhypoxic conditions.

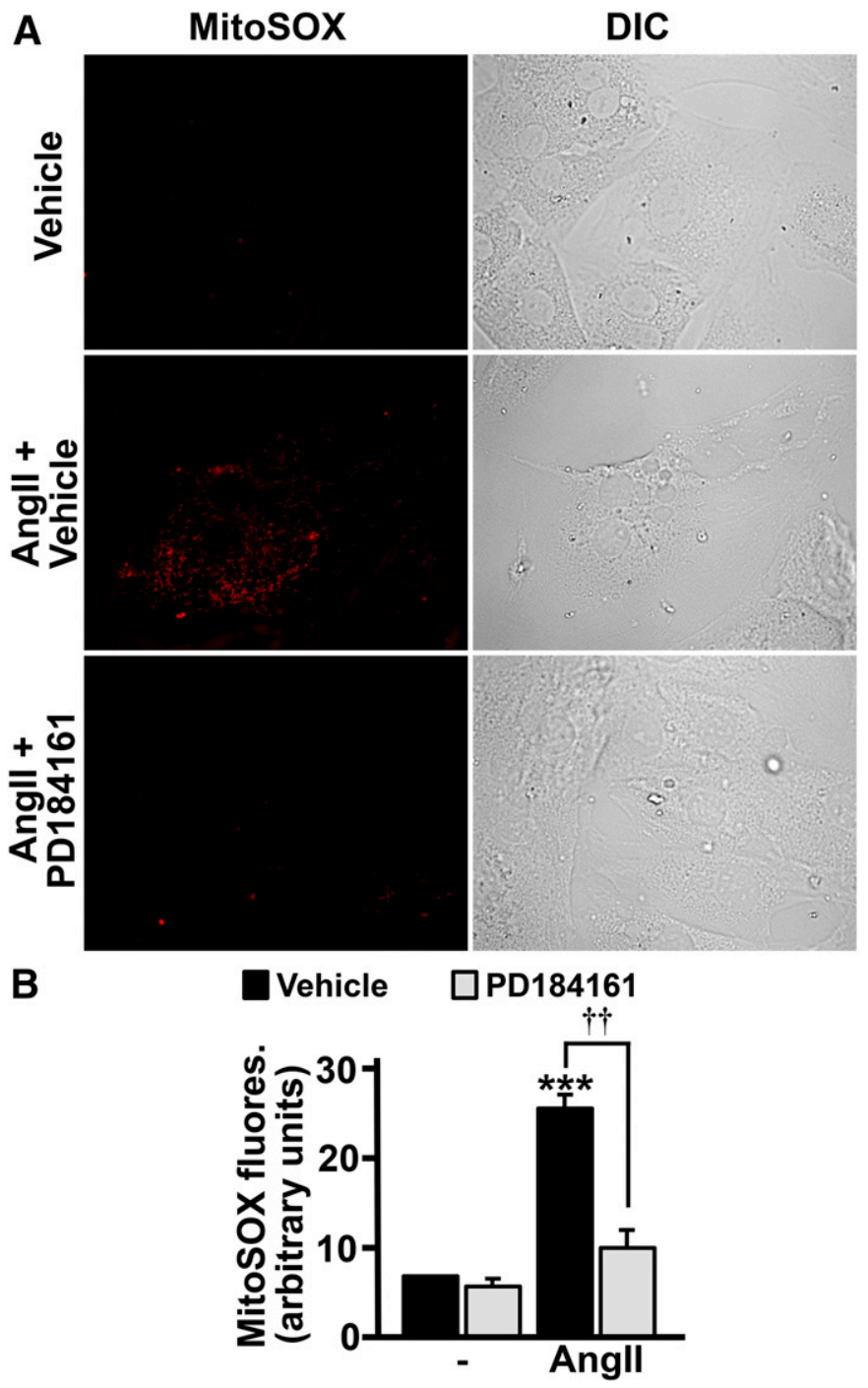

Fig. 5. PD184161 influences mtROS production by AngII. (A) VSMC, seeded on 35-mm glass-bottomed cell culture dishes, were incubated with MitoSOX $(1 \mu \mathrm{M})$ for a total of 1 hour. Twenty minutes after adding MitoSOX, cells were pretreated or not with PD184161 (50 nM). Twenty minutes before imaging, VSMC were treated with AngII (100 nM). Differential interference contrast (DIC) was used for whole-cell imaging and subsequent quantification. (B) Quantification of measurements in (A) are expressed as arbitrary units of MitoSOX fluorescence and are an average with S.D. of three independent experiments; $n=50$ cells. $* * * P<0.001$ compared with untreated VSMC. ${ }^{\dagger \dagger} P<0.01$ compared with indicated conditions.
PD184161 Inhibits Mitochondrial Membrane Potential Depolarization and ATP Production in AngII-Treated VMSC. Depolarization of mitochondrial membrane potential $\left(\Delta \Psi_{\mathrm{M}}\right)$ is known to influence mtROS generation in VSMC (Kimura et al., 2005a). To determine if PD184161 affects $\Delta \Psi_{\mathrm{M}}$ in AngII-treated VSMC, we analyzed $\Delta \Psi_{\mathrm{M}}$ using TMRM. As seen in Fig. 7, A and B, VSMC treated with AngII showed decreased TMRM staining compared with untreated cells, an indication of $\Delta \Psi_{\mathrm{M}}$ depolarization. More interestingly, pretreatment of VSMC with PD184161 restored $\Delta \Psi_{\mathrm{M}}$ under AngII treatment. These results indicate that the maintenance of mitochondrial membrane potential by PD184161 may be responsible for inhibition of mtROS generation.

ATP is essential for the opening of mitochondrial ATPsensitive potassium channels $\left(\right.$ mitoK $_{\mathrm{ATP}}$ ), a main mediator of $\Delta \Psi_{\mathrm{M}}$ depolarization. PD184161 was previously shown to affect ATP production (Yung et al., 2004). As seen in Fig. 7C, VSMC pretreated with PD184161 show decreased ATP production in comparison with untreated cells. These results indicate that PD184161 may decrease HIF-1 levels induced under nonhypoxic conditions by modifying both ATP production and $\Delta \Psi_{\mathrm{M}}$ depolarization. These two phenomena could therefore re-establish mtROS generation and cellular ascorbate levels to those seen in untreated cells.

\section{Discussion}

By blocking the p42/p44 MAPK signaling pathway, MEK1/2 inhibitors such as PD98059 act as negative regulators of HIF-1 transcriptional activity (Richard et al., 1999; Minet et al., 2000; Hur et al., 2001; Sodhi et al., 2001; Fukuda et al., 2002; Lee et al., 2002; Sutton et al., 2007). The present study demonstrates that PD184161, another potent MEK1/2 inhibitor, is also a selective inhibitor of nonhypoxic HIF- $1 \alpha$ protein accumulation in VSMC. More specifically, we show that PD184161 strikingly decreased HIF-1 $\alpha$ protein levels during AngII treatment by blocking associated mtROS generation, re-establishing cellular ascorbate levels, restoring proteasomal targeting by VHL, and finally, HIF$1 \alpha$ proteasomal degradation.

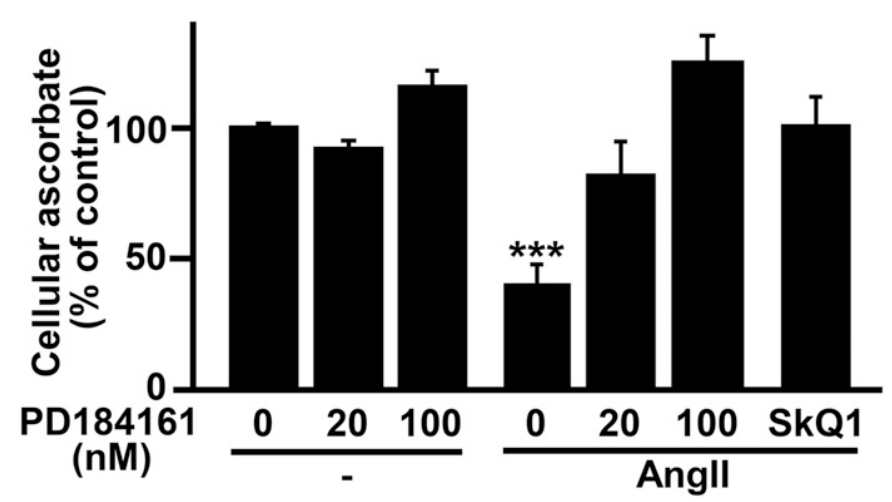

Fig. 6. PD184161 affects intracellular levels of ascorbate. Quiescent VSMC were cultured in ascorbate-supplemented DMEM and pretreated or not with PD184161 (at indicated concentrations) or SkQ1 (250 nM). VSMC were then treated with AngII (100 nM) for 4 hours. Cells were washed twice with phosphate-buffered saline and resuspended in methanol. Ascorbate concentrations were determined using a protocol with differential spectrometric measurements as a basis (see Materials and Methods). Results are expressed as the percentage of relative intracellular ascorbate levels compared with untreated cells and are an average with S.D. of three independent experiments. ${ }^{* * *} P<0.001$ compared with untreated cells. 
A

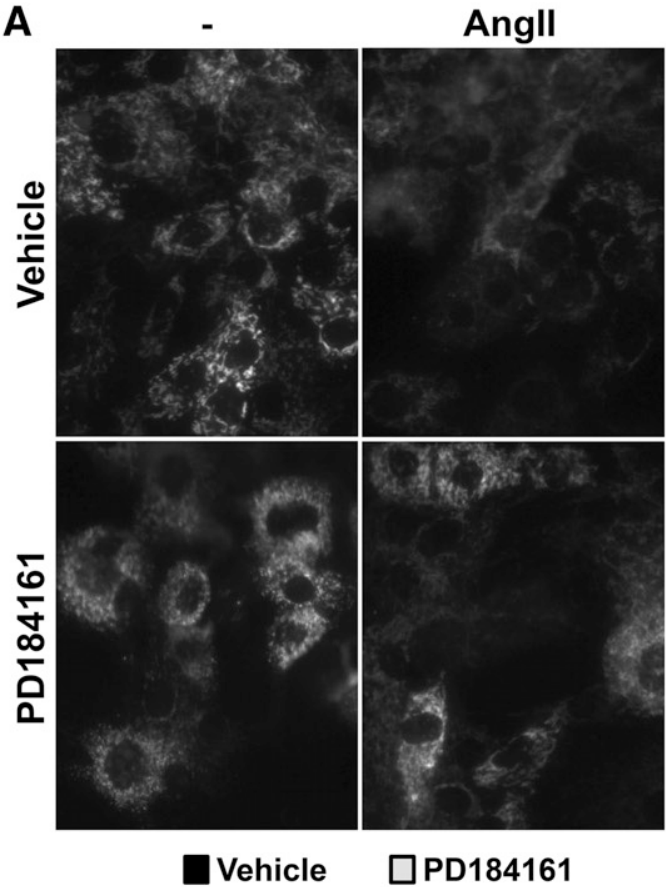

B

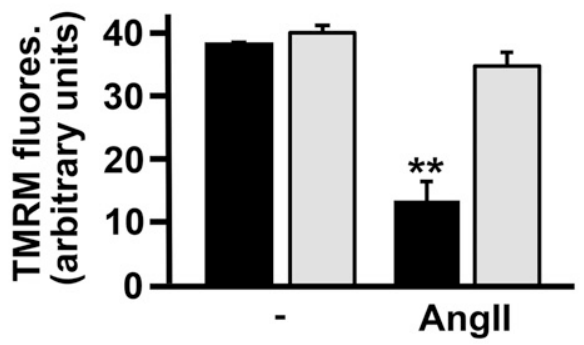

C

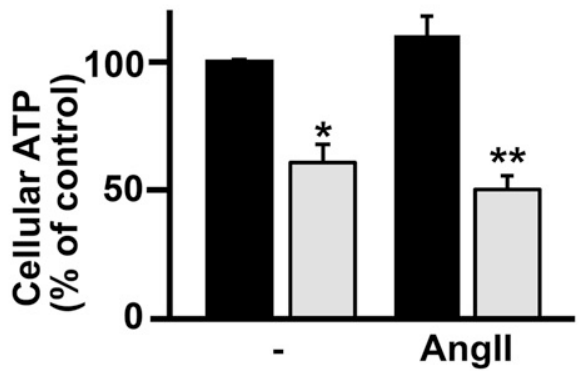

Fig. 7. PD184161 inhibits mitochondrial membrane potential depolarization and ATP production. (A) VSMC cells, seeded on 35-mm glass-bottomed cell culture dishes, were pretreated or not with PD184161 (50 nM) for 20 minutes and treated with AngII (100 nM) for 40 minutes. Cells were then incubated with TMRM (200 nM) for 20 minutes before imaging. (B) Quantification of measurements in (A) are expressed as arbitrary units of TMRM fluorescence and are an average with S.D. of three independent experiments, $n=50$ cells. ${ }^{*} P<0.01$ compared with untreated VSMC. (C) Quiescent VSMC were pretreated or not with PD184161 (50 nM) for 20 minutes and then treated with AngII (100 nM) for 1 hour. ATP levels were measured as described in Materials and Methods. Results are expressed as the percentage of relative ATP levels compared with untreated cells and are an average with S.D. of three independent experiments. $* P<0.05$; $* * P<0.01$ compared with untreated cells.

In VSMC, AngII is a strong activator of the p42/p44 MAPK pathway through EGFR transactivation as well as being a potent HIF-1 inducer (Lauzier et al., 2007). p42/p44 MAPK pathway activation by AngII enhances HIF-1 transcriptional activity by promoting direct HIF-1 $\alpha$ phosphorylation (Lauzier et al., 2007). Pin1, a proline isomerase, can recognize this phosphorylation, modify HIF-1 $\alpha$ conformation, and enhance HIF-1-related gene transcription (Jalouli et al., 2014). However, in AngII-treated VSMC and other systems, p42/p44 MAPK pathway activation has only modest effects on HIF-1 $\alpha$ protein induction (Berra et al., 2001; Lauzier et al., 2007). In fact, inhibition of EGFR and p42/p44 MAPK activation by AG1478 or PD98059, respectively, only causes a slight decrease in AngII-increased HIF- $1 \alpha$ levels (Lauzier et al., 2007). Consistent with these studies, we show here that unlike PD184161, PD98059 only modestly affects HIF- $1 \alpha$ induction by AngII in conditions where p42/p44 MAPK activation is completely abolished. Given the potency of PD184161 to block HIF-1 $\alpha$ induction during VSMC stimulation with AngII, our results indicate that PD184161 influences HIF-1 $\alpha$ protein levels through a mechanism distinct from its inhibitory effect on p42/p44 MAPK.

In addition to AngII, other nonhypoxic stimuli, such as Thr, $\mathrm{S} 1 \mathrm{P}$, and PDGF, are also able to induce HIF-1 $\alpha$ protein levels in VSMC through similar mechanisms. Our present study clearly shows that PD184161 selectively abolishes nonhypoxic HIF-1 $\alpha$ induction without interfering with hypoxic HIF-1 induction. We decided to investigate how this compound negatively impacts mechanisms involved in nonhypoxic HIF1 induction. Our previous studies demonstrated that the main mechanism by which AngII induces HIF- $1 \alpha$ protein is through the inhibition of PHD enzymatic activity, which leads to decreased HIF-1 $\alpha$ hydroxylation, VHL binding, ubiquitination, and proteasomal degradation (Pagé et al., 2008). mtROS generation is important for AngII-induced HIF-1 $\alpha$, most probably by the Fenton reaction $\left(\mathrm{Fe}^{2+}\right.$ oxidation to $\mathrm{Fe}^{3+}$ ) resulting in decreased intracellular ascorbate levels (Gerald et al., 2004; Bell et al., 2007). Indeed, inhibition of mtROS production was shown to negatively regulate AngII-induced HIF-1 $\alpha$ accumulation (Pagé et al., 2008; Patten et al., 2010). Accordingly, we show here that PD184161 promotes HIF-1 $\alpha$ proteasomal degradation, increased hydroxylation and VHL binding, inhibition of AngII-induced mtROS generation production, and the re-establishment of intracellular ascorbate availability. Previous studies demonstrated that $\mathrm{p} 42 / \mathrm{p} 44$ MAPK activity is not implicated in the HIF-1 $\alpha$ stability (Berra et al., 2001). This supports our findings that the effect of PD184161 on HIF- $1 \alpha$ protein induction is independent of p42/p44 MAPK pathway inhibition.

The mitochondrial respiratory chain represents a major source of ROS (Pagé et al., 2008; Camara et al., 2010; Dedkova et al., 2013; Dröse, 2013; Wojtovich et al., 2013). Our previous work demonstrated that HIF-1 $\alpha$ induction by AngII requires mitochondrial/complex III generated mtROS (Patten et al., 2010). Hence, PD184161 may reduce AngII-mediated HIF-1 $\alpha$ accumulation by blocking mitochondrial respiratory chain function. Interestingly, unlike PD98059, PD184161 can induce a profound ATP depletion by modulating ATP synthase activity in a manner similar to oligomycin A, a mitochondrial ATP synthase inhibitor (Yung et al., 2004). ATP synthase inhibition, and thus changes in oxidative phosphorylation, was shown to negatively regulate ROS production (Santamaría et al., 2006). A second study indicated that in addition to inhibiting MEK1/2, PD184161 caused cell death in glucose-deprived cells, a result of profound ATP depletion caused by ATP-synthase inhibition (Yung et al., 2004). Accordingly, we show decreased ATP levels under PD184161 treatment in VSMC. It is therefore probable that reduced AngII-induced mtROS generation under PD184161 treatment 
is a result of decreased ATP synthase activity and lower ATP levels. In addition, depolarization of mitochondrial membrane potential through the opening of mitoK $_{\mathrm{ATP}}$ was shown to be implicated in AngII-induced mtROS generation (Kimura et al., 2005a). It was reported that kinase inhibitors can affect protein function and act as competitors for ATP binding proteins by forming aggregates (Hanks et al., 1988; Halestrap, 1999; Davies et al., 2000; Genini et al., 2000; Xue et al., 2002; Bain et al., 2003; McGovern and Shoichet, 2003). We show that PD184161 exerts a negative effect on mitochondrial membrane depolarization in response to AngII treatment in VSMC. This further indicates that decreased ATP, mitoK $\mathrm{K}_{\mathrm{ATP}}$ channel activity, and depolarization of the $\Delta \Psi \mathrm{M}$ could be involved in decreased mtROS generation and decreased HIF-1 induction in VSMCs during nonhypoxic activation.

AngII is an important regulator for many physiopathological processes such as hypertension, atherosclerosis, VSMC remodeling, and fibrosis (Hanna et al., 2002; Touyz, 2003; Heeneman et al., 2007). p42/p44 MAPK pathway activation is implicated in mediating the effects of AngII (Ishida et al., 1998; Ishida et al., 1999; Queval and Noctor, 2007; Wang et al., 2015). By activating genes involved in the control of several cell functions, HIF-1 is also implicated in a number of AngII-induced degenerative diseases, such as cardiovascular and kidney diseases (Zhu et al., 2011; Imanishi et al., 2014; Luo et al., 2015; Obama et al., 2015). Because of the important role of HIF-1 in disease progression, targeting it has gained significant interest. Our study demonstrates that PD184161 is a potent inhibitor of AngII-induced HIF- $1 \alpha$ protein induction and identifies this compound as a potential treatment strategy. PD184161 has an added advantage since it inhibits HIF- $1 \alpha$ by blocking mtROS production, an important mediator of AngII-activated responses (Kimura et al., 2005a,b; Caldiz et al., 2007; De Giusti et al., 2008, 2009; Doughan et al., 2008; Patten et al., 2010; Caldiz et al., 2011). In addition, mice expressing mitochondriatargeted catalase were resistant to AngII-dependent cardiac hypertrophy, autophagy, fibrosis, and mitochondrial damage (Dai and Rabinovitch, 2011). Therefore, we believe that PD184161 may be therapeutically interesting for further studies concerning the physiopathological roles of AngII.

In summary, our study identifies PD184161 as a robust inhibitor of nonhypoxic HIF-1 induction. PD184161 is a potent p42/p44 MAPK pathway inhibitor, and the present work now identifies it as an HIF-1 $\alpha$ inhibitor by way of blocking mtROS generation in VSMC. Given the importance of the implication of the p42/p44 MAPK pathway, ROS, and HIF-1 in several AngII-mediated physiologic and physiopathological processes, we believe that these studies have an interesting impact in AngII-related vascular biology.

\section{Acknowledgments}

The authors thank Dr. Jacques Pouysségur, Dr. Peter Ratcliffe, Dr. Richard K. Bruick, and Dr. Gregg Semenza for the GST-HIF-1 $\alpha$, VHL-HA, luc-HIF-1 $\alpha$ ODDD constructs, and pHIF-1A-572/+32Luc reporter vector, respectively. The authors also thank Dr. Josée N. Lavoie for technical support in the use of the Zeiss microscope.

\section{Authorship Contributions}

Participated in research design: Jalouli, Richard.

Conducted experiments: Jalouli, Mokas, Turgeon, Lamalice.

Performed data analysis: Jalouli, Mokas, Lamalice, Richard.

Wrote or contributed to the writing of the manuscript: Jalouli, Mokas, Turgeon, Lamalice, Richard.

\section{References}

Bain J, McLauchlan H, Elliott M, and Cohen P (2003) The specificities of protein kinase inhibitors: an update. Biochem $J$ 371:199-204.

Bell EL, Klimova TA, Eisenbart J, Moraes CT, Murphy MP, Budinger GR, and Chandel NS (2007) The Qo site of the mitochondrial complex III is required for the transduction of hypoxic signaling via reactive oxygen species production. $J$ Cell Biol 177:1029-1036.

Berra E, Richard DE, Gothié E, and Pouysségur J (2001) HIF-1-dependent transcriptional activity is required for oxygen-mediated HIF-1alpha degradation. FEBS Lett 491:85-90.

Caldiz CI, Garciarena CD, Dulce RA, Novaretto LP, Yeves AM, Ennis IL, Cingolani HE, Chiappe de Cingolani G, and Pérez NG (2007) Mitochondrial reactive oxygen species activate the slow force response to stretch in feline myocardium. J Physiol 584:895-905.

Caldiz CI, Díaz RG, Nolly MB, Chiappe de Cingolani GE, Ennis IL, Cingolani HE, and Pérez NG (2011) Mineralocorticoid receptor activation is crucial in the signalling pathway leading to the Anrep effect. J Physiol 589:6051-6061.

Camara AK, Lesnefsky EJ, and Stowe DF (2010) Potential therapeutic benefits of strategies directed to mitochondria. Antioxid Redox Signal 13:279-347.

Cockman ME, Masson N, Mole DR, Jaakkola P, Chang GW, Clifford SC, Maher ER, Pugh CW, Ratcliffe PJ, and Maxwell PH (2000) Hypoxia inducible factor-alpha binding and ubiquitylation by the von Hippel-Lindau tumor suppressor protein. $J$ Biol Chem 275:25733-25741.

Dai DF and Rabinovitch P (2011) Mitochondrial oxidative stress mediates induction of autophagy and hypertrophy in angiotensin-II treated mouse hearts. Autophagy 7:917-918.

Davies SP, Reddy H, Caivano M, and Cohen P (2000) Specificity and mechanism of action of some commonly used protein kinase inhibitors. Biochem $J$ 351:95-105.

Dedkova EN, Seidlmayer LK, and Blatter LA (2013) Mitochondria-mediated cardioprotection by trimetazidine in rabbit heart failure. $J$ Mol Cell Cardiol 59:41-54.

De Giusti VC, Correa MV, Villa-Abrille MC, Beltrano C, Yeves AM, de Cingolani GE, Cingolani HE, and Aiello EA (2008) The positive inotropic effect of endothelin-1 is mediated by mitochondrial reactive oxygen species. Life Sci 83:264-271.

De Giusti VC, Garciarena CD, and Aiello EA (2009) Role of reactive oxygen species (ROS) in angiotensin II-induced stimulation of the cardiac $\mathrm{Na}+/ \mathrm{HCO} 3-\mathrm{co}-$ transport. J Mol Cell Cardiol 47:716-722.

de Jong L, Albracht SP, and Kemp A (1982) Prolyl 4-hydroxylase activity in relation to the oxidation state of enzyme-bound iron. The role of ascorbate in peptidyl proline hydroxylation. Biochim Biophys Acta 704:326-332.

Doughan AK, Harrison DG, and Dikalov SI (2008) Molecular mechanisms of angiotensin II-mediated mitochondrial dysfunction: linking mitochondrial oxidative damage and vascular endothelial dysfunction. Circ Res 102:488-496.

Dröse S (2013) Differential effects of complex II on mitochondrial ROS production and their relation to cardioprotective pre- and postconditioning. Biochim Biophys Acta 1827:578-587.

Epstein AC, Gleadle JM, McNeill LA, Hewitson KS, O'Rourke J, Mole DR, Mukherji M, Metzen E, Wilson MI, Dhanda A, et al. (2001) C. elegans EGL-9 and mammalian homologs define a family of dioxygenases that regulate HIF by prolyl hydroxylation. Cell 107:43-54.

Fukuda R, Hirota K, Fan F, Jung YD, Ellis LM, and Semenza GL (2002) Insulin-like growth factor 1 induces hypoxia-inducible factor 1-mediated vascular endothelial growth factor expression, which is dependent on MAP kinase and phosphatidylinositol 3-kinase signaling in colon cancer cells. J Biol Chem 277:38205-38211.

Genini D, Adachi S, Chao Q, Rose DW, Carrera CJ, Cottam HB, Carson DA, and Leoni LM (2000) Deoxyadenosine analogs induce programmed cell death in chronic lymphocytic leukemia cells by damaging the DNA and by directly affecting the mitochondria. Blood 96:3537-3543.

Gerald D, Berra E, Frapart YM, Chan DA, Giaccia AJ, Mansuy D, Pouysségur J, Yaniv M, and Mechta-Grigoriou F (2004) JunD reduces tumor angiogenesis by protecting cells from oxidative stress. Cell 118:781-794.

Halestrap AP (1999) The mitochondrial permeability transition: its molecular mechanism and role in reperfusion injury. Biochem Soc Symp 66:181-203.

Han HJ, Kwon N, Choi MA, Jung KO, Piao JY, Ngo HK, Kim SJ, Kim DH, Chung JK, Cha YN, et al. (2016) Peptidyl prolyl isomerase PIN1 directly binds to and stabilizes hypoxia-inducible factor-1 $\alpha$. PLoS One 11:e0147038.

Hanks SK, Quinn AM, and Hunter T (1988) The protein kinase family: conserved features and deduced phylogeny of the catalytic domains. Science 241:42-52.

Hanna IR, Taniyama Y, Szöcs K, Rocic P, and Griendling KK (2002) NAD(P)H oxidase-derived reactive oxygen species as mediators of angiotensin II signaling. Antioxid Redox Signal 4:899-914.

Heeneman S, Sluimer JC, and Daemen MJ (2007) Angiotensin-converting enzyme and vascular remodeling. Circ Res 101:441-454.

Huang LE, Gu J, Schau M, and Bunn HF (1998) Regulation of hypoxia-inducible factor 1alpha is mediated by an O2-dependent degradation domain via the ubiquitin-proteasome pathway. Proc Natl Acad Sci USA 95:7987-7992.

Hur E, Chang KY, Lee E, Lee SK, and Park H (2001) Mitogen-activated protein kinase kinase inhibitor PD98059 blocks the trans-activation but not the stabilization or DNA binding ability of hypoxia-inducible factor-1alpha. Mol Pharmacol 59:1216-1224.

Imanishi M, Tomita S, Ishizawa K, Kihira Y, Ueno M, Izawa-Ishizawa Y, Ikeda Y, Yamano N, Tsuchiya K, and Tamaki T (2014) Smooth muscle cell-specific Hif-1 $\alpha$ deficiency suppresses angiotensin II-induced vascular remodelling in mice. Cardiovasc Res 102:460-468. Ishida M, Ishida T, Thomas SM, and Berk BC (1998) Activation of extracellular signal-regulated kinases (ERK1/2) by angiotensin II is dependent on c-Src in vascular smooth muscle cells. Circ Res 82:7-12.

Ishida T, Ishida M, Suero J, Takahashi M, and Berk BC (1999) Agonist-stimulated cytoskeletal reorganization and signal transduction at focal adhesions in vascular smooth muscle cells require c-Src. J Clin Invest 103:789-797.

Ivan M, Kondo K, Yang H, Kim W, Valiando J, Ohh M, Salic A, Asara JM, Lane WS, and Kaelin WG, Jr (2001) HIFalpha targeted for VHL-mediated destruction by proline hydroxylation: implications for O2 sensing. Science 292:464-468. 
Jaakkola P, Mole DR, Tian YM, Wilson MI, Gielbert J, Gaskell SJ, von Kriegsheim A, Hebestreit HF, Mukherji M, Schofield CJ, et al. (2001) Targeting of HIF-alpha to the von Hippel-Lindau ubiquitylation complex by O2-regulated prolyl hydroxylation. Science 292:468-472

Jalouli M, Déry MA, Lafleur VN, Lamalice L, Zhou XZ, Lu KP, and Richard DE (2014) The prolyl isomerase Pin1 regulates hypoxia-inducible transcription factor (HIF) activity. Cell Signal 26:1649-1656.

Kaelin WG Jr and Ratcliffe PJ (2008) Oxygen sensing by metazoans: the central role of the HIF hydroxylase pathway. Mol Cell 30:393-402.

Kimura S, Zhang GX, Nishiyama A, Shokoji T, Yao L, Fan YY, Rahman M, and Abe Y (2005a) Mitochondria-derived reactive oxygen species and vascular MAP kinases: comparison of angiotensin II and diazoxide. Hypertension 45:438-444.

Kimura S, Zhang GX, Nishiyama A, Shokoji T, Yao L, Fan YY, Rahman M, Suzuki T, Maeta H, and Abe Y (2005b) Role of NAD(P)H oxidase- and mitochondria-derived reactive oxygen species in cardioprotection of ischemic reperfusion injury by angiotensin II. Hypertension 45:860-866.

Klein PJ, Schmidt CM, Wiesenauer CA, Choi JN, Gage EA, Yip-Schneider MT, Wiebke EA, Wang Y, Omer C, and Sebolt-Leopold JS (2006) The effects of a novel MEK inhibitor PD184161 on MEK-ERK signaling and growth in human liver cancer. Neoplasia 8:1-8.

Lauzier MC, Pagé EL, Michaud MD, and Richard DE (2007) Differential regulation of hypoxia-inducible factor-1 through receptor tyrosine kinase transactivation in vascular smooth muscle cells. Endocrinology 148:4023-4031.

Lee E, Yim S, Lee SK, and Park H (2002) Two transactivation domains of hypoxiainducible factor-1alpha regulated by the MEK-1/p42/p44 MAPK pathway. Mol Cells 14:9-15.

Luo R, Zhang W, Zhao C, Zhang Y, Wu H, Jin J, Zhang W, Grenz A, Eltzschig HK, Tao L, et al. (2015) Elevated endothelial hypoxia-inducible factor- $1 \alpha$ contributes to glomerula injury and promotes hypertensive chronic kidney disease. Hypertension 66:75-84.

Majamaa K, Günzler V, Hanauske-Abel HM, Myllylä R, and Kivirikko KI (1986) Partial identity of the 2-oxoglutarate and ascorbate binding sites of prolyl 4-hydroxylase. J Biol Chem 261:7819-7823.

Marshall SJ, Senis YA, Auger JM, Feil R, Hofmann F, Salmon G, Peterson JT, Burslem $\mathrm{F}$, and Watson SP (2004) GPIb-dependent platelet activation is dependent on Src kinases but not MAP kinase or cGMP-dependent kinase. Blood 103:2601-2609.

Maxwell PH, Wiesener MS, Chang GW, Clifford SC, Vaux EC, Cockman ME, Wykoff CC, Pugh CW, Maher ER, and Ratcliffe PJ (1999) The tumour suppressor protein VHL targets hypoxia-inducible factors for oxygen-dependent proteolysis. Nature 399:271-275.

McGovern SL and Shoichet BK (2003) Kinase inhibitors: not just for kinases anymore. J Med Chem 46:1478-1483.

Michaud MD, Robitaille GA, Gratton JP, and Richard DE (2009) Sphingosine-1phosphate: a novel nonhypoxic activator of hypoxia-inducible factor-1 in vascular cells. Arterioscler Thromb Vasc Biol 29:902-908.

Minet E, Arnould T, Michel G, Roland I, Mottet D, Raes M, Remacle J, and Michiels C (2000) ERK activation upon hypoxia: involvement in HIF-1 activation. FEBS Lett 468:53-58.

Mylonis I, Chachami G, Samiotaki M, Panayotou G, Paraskeva E, Kalousi A Georgatsou E, Bonanou S, and Simos G (2006) Identification of MAPK phosphorylation sites and their role in the localization and activity of hypoxiainducible factor-1alpha. J Biol Chem 281:33095-33106.

Obama T, Takayanagi T, Kobayashi T, Bourne AM, Elliott KJ, Charbonneau M, Dubois CM, and Eguchi S (2015) Vascular induction of a disintegrin and metalloprotease 17 by angiotensin II through hypoxia inducible factor $1 \alpha$. Am J Hypertens 28:10-14.

Owens GK, Loeb A, Gordon D, and Thompson MM (1986) Expression of smooth muscle-specific alpha-isoactin in cultured vascular smooth muscle cells: relationship between growth and cytodifferentiation. J Cell Biol 102:343-352.

Pagé EL, Chan DA, Giaccia AJ, Levine M, and Richard DE (2008) Hypoxia-inducible factor-1alpha stabilization in nonhypoxic conditions: role of oxidation and in tracellular ascorbate depletion. Mol Biol Cell 19:86-94

Pagé EL, Robitaille GA, Pouysségur J, and Richard DE (2002) Induction of hypoxiainducible factor-1alpha by transcriptional and translational mechanisms. $J$ Biol Chem 277:48403-48409.
Patten DA, Lafleur VN, Robitaille GA, Chan DA, Giaccia AJ, and Richard DE (2010) Hypoxia-inducible factor-1 activation in nonhypoxic conditions: the essential role of mitochondrial-derived reactive oxygen species. Mol Biol Cell 21:3247-3257.

Pfaffl MW (2001) A new mathematical model for relative quantification in real-time RT-PCR. Nucleic Acids Res 29:e45.

Queval G and Noctor G (2007) A plate reader method for the measurement of NAD, NADP, glutathione, and ascorbate in tissue extracts: application to redox profiling during Arabidopsis rosette development. Anal Biochem 363:58-69.

Richard DE, Berra E, Gothié E, Roux D, and Pouysségur J (1999) p42/p44 mitogenactivated protein kinases phosphorylate hypoxia-inducible factor 1alpha (HIF1alpha) and enhance the transcriptional activity of HIF-1. J Biol Chem 274: 32631-32637.

Richard DE, Berra E, and Pouyssegur J (2000) Nonhypoxic pathway mediates the induction of hypoxia-inducible factor 1alpha in vascular smooth muscle cells. J Biol Chem 275:26765-26771.

Salnikow K, Donald SP, Bruick RK, Zhitkovich A, Phang JM, and Kasprzak KS (2004) Depletion of intracellular ascorbate by the carcinogenic metals nickel and cobalt results in the induction of hypoxic stress. J Biol Chem 279:40337-40344.

Santamaría G, Martínez-Diez M, Fabregat I, and Cuezva JM (2006) Efficient execution of cell death in non-glycolytic cells requires the generation of ROS controlled by the activity of mitochondrial H+-ATP synthase. Carcinogenesis 27:925-935.

Schofield CJ and Ratcliffe PJ (2005) Signalling hypoxia by HIF hydroxylases. Biochem Biophys Res Commun 338:617-626.

Semenza GL (2003) Targeting HIF-1 for cancer therapy. Nat Rev Cancer 3:721-732. Skulachev VP, Anisimov VN, Antonenko YN, Bakeeva LE, Chernyak BV, Erichev VP, Filenko OF, Kalinina NI, Kapelko VI, Kolosova NG, et al. (2009) An attempt to prevent senescence: a mitochondrial approach. Biochim Biophys Acta 1787 437-461.

Sodhi A, Montaner S, Miyazaki H, and Gutkind JS (2001) MAPK and Akt act cooperatively but independently on hypoxia inducible factor-1alpha in rasV12 upregulation of VEGF. Biochem Biophys Res Commun 287:292-300.

Sutton KM, Hayat S, Chau NM, Cook S, Pouyssegur J, Ahmed A, Perusinghe N, Le Floch R, Yang J, and Ashcroft M (2007) Selective inhibition of MEK1/2 reveals a differential requirement for ERK1/2 signalling in the regulation of HIF-1 in response to hypoxia and IGF-1. Oncogene 26:3920-3929.

Thottassery JV, Sun Y, Westbrook L, Rentz SS, Manuvakhova M, Qu Z, Samuel S, Upshaw R, Cunningham A, and Kern FG (2004) Prolonged extracellular signalregulated kinase 1/2 activation during fibroblast growth factor 1- or heregulin beta1-induced antiestrogen-resistant growth of breast cancer cells is resistant to mitogen-activated protein/extracellular regulated kinase kinase inhibitors. Cancer Res 64:4637-4647.

Touyz RM (2003) The role of angiotensin II in regulating vascular structural and functional changes in hypertension. Curr Hypertens Rep 5:155-164.

Wang C, Qian X, Sun X, and Chang Q (2015) Angiotensin II increases matrix metalloproteinase 2 expression in human aortic smooth muscle cells via AT1R and ERK1/2. Exp Biol Med (Maywood) 240:1564-1571.

Wojtovich AP, Smith CO, Haynes CM, Nehrke KW, and Brookes PS (2013) Physiological consequences of complex II inhibition for aging, disease, and the mKATP channel. Biochim Biophys Acta 1827:598-611.

Xue L, Borutaite V, and Tolkovsky AM (2002) Inhibition of mitochondrial permeability transition and release of cytochrome $\mathrm{c}$ by anti-apoptotic nucleoside analogues. Biochem Pharmacol 64:441-449.

Yung HW, Wyttenbach A, and Tolkovsky AM (2004) Aggravation of necrotic death of glucose-deprived cells by the MEK1 inhibitors U0126 and PD184161 through depletion of ATP. Biochem Pharmacol 68:351-360.

Zhu Q, Wang Z, Xia M, Li PL, Van Tassell BW, Abbate A, Dhaduk R, and Li N (2011) Silencing of hypoxia-inducible factor- $1 \alpha$ gene attenuated angiotensin II-induced renal injury in Sprague-Dawley rats. Hypertension 58:657-664.

Address correspondence to: Dr. Darren E. Richard, Centre de recherche du CHU de Québec, L'Hôtel-Dieu de Québec, 9 Rue McMahon, Québec City, QC G1R 3S3, Canada. E-mail: darren.richard@crchudequebec.ulaval.ca 